\title{
A ARTE COMO ELEMENTO DE PODER E PROPAGANDA NO IMPÉRIO NEOASSÍRIO
}

Art as an element of power and propaganda in the Neo-Assyrian Empire 


\title{
RESUMO
}

Este artigo tem como objetivo apresentar o propósito da arte no império neoassírio, seu contexto histórico e suas ramificações neste período. Para se alcançar esse objetivo, uma revisão de literatura a respeito da arte no Império Neoassírio, e de documentos históricos e arqueológicos foi realizada. Pode-se observar que, ao contrário da percepção geral, os palácios neoassírios não se restringiam meramente a um complexo residencial real, mas também possuíam uma função político-social. Os palácios, a partir do reinado de Assurnasirpal II, foram decorados com temas mesopotâmicos tradicionais, mas as esculturas e os relevos artísticos presentes não tinham apenas o objetivo de decorar o palácio e sim estabelecer o direito divino real perante seus súditos, especialmente a elite da qual o rei era dependente politicamente. Essas características artísticas palacianas permaneceram ao longo dos séculos e tiveram seu auge durante o reinado de Senaqueribe, durante o qual também foi possível constatar inovações artísticas. Ao examinar as evidências arqueológicas e históricas de seu palácio e contrastá-las, foi possível identificar várias discrepâncias entre si, principalmente no que se refere à audiência. Pode-se se concluir, ao considerar como exemplo a tomada da cidade de Laquis no palácio de Senaqueribe, que as esculturas e relevos artísticos poderiam ser direcionados a uma determinada audiência, e que eles, ao contrário de documentos escritos, omitiam certos acontecimentos que permaneciam acessíveis somente às pessoas de confiança do rei.

\section{PALAVRAS-CHAVE}

Império Neoassírio. Relevos artísticos. Propaganda assíria.

\begin{abstract}
The present article aims to introduce the purpose of art in the Neo-Assyrian Empire, its historical context and ramifications during this period. For this purpose, we performed a literature review of the art in the Neo-Assyrian Empire and in historical and archaeological documents. Contrary to general perception, the Neo-Assyrian palaces were not only restricted to a royal residence complex, but they also had a social-political function. By the time of Ashurnasirpal II, the palaces were decorated with Mesopotamian traditional motifs, but its sculptures and artistic reliefs were not only intended to decorate the palace, but to establish the royal right before their subjects, especially the elite that the king depended upon politically. These palatial artistic features remained over the centuries and peaked during the reign of Sennacherib, where it is possible to notice artistic innovations. In examining the archaeological and historical evidences of his palace and contrast them, it is possible to identify many discrepancies, mainly concerning his intended audience. We are able to conclude, taking the Lachish assault in the palace of Sennacherib as an example, that sculptures and artistic reliefs could be targeted to a determined audience and, unlike written documents, they omitted certain events that would remain accessible only to people whom the king trusted.
\end{abstract}

\section{KEYWORDS}

Neo-Assyrian Empire. Artistic reliefs. Assyrian propaganda. 
$\mathbf{A}$ s diversas formas de arte provenientes da mesopotâmia são conhecidas pela miríade de temas, que se estendem desde a elaboração de pequenas esculturas representando divindades protetoras para o afastamento de doenças e má sorte, estelas como a de Hamurabi que apresentam códigos de leis e uma representação artística humana e divina, além de relevos artísticos demonstrando os feitos públicos do rei, como a caça e as conquistas militares. No entanto, é a partir do estabelecimento do Império Neoassírio que esse estilo de arte, herdado há vários séculos de povos mesopotâmicos é estabelecido de forma sistemática. A partir do reinado de Assurnasirpal II, a arte assíria começa a passar por mudanças significativas, não apenas em sua elaboração, mas em sua organização dentro e fora dos palácios. A distribuição dos cômodos do palácio de forma sistêmica tinha como objetivo alcançar certa audiência no palácio e determinar a esta certos conceitos que o rei pretendia estabelecer. Estes objetivos tornam-se claros ao se examinarem as evidências literárias e arqueológicas do palácio de Senaqueribe, que não apenas deram prosseguimento às mudanças de Assurnasirpal II, mas também expandiram as inovações artísticas nos relevos, influenciando na maneira como a arte era elaborada até o período de Assurbanipal. Pesquisar o pano de fundo histórico, os relatórios de campo arqueológicos, a arte assíria e os anais de Senaqueribe são a chave para se compreender as razões que levaram os governantes assírios a estruturar os seus palácios para acomodar a arte, e também a desenvolvê-la de forma que pudessem alcançar certa audiência. Por intermédio de uma revisão bibliográfica, será possível compreender não apenas o contexto histórico, mas também a ideologia do Império Neoassírio, e a forma como os monarcas poderiam utilizar essa ideologia a seu favor como meio propagandístico de seu governo para alcançar estabilidade no trono.

\section{CONTEXTO HISTÓRICO E IDEOLÓGICO DO IMPÉRIO NEOASSÍRIO}

Ao redor do segundo milênio a.C., a Assíria, que já havia se consolidado há vários séculos como um reino próspero, passou por um período de declínio e obscuridade causado por vários fatores, mas entre os principais estavam os invasores arameus e o estabelecimento de seus reinados no território assírio. A Assíria foi reduzida a uma área que correspondia a sua capital Assur e seus arredores. Esse período, chamado "Período das Trevas" pelos assiriólogos, durou de 1050 a 900 a.C. De acordo com McLaughlin (2012, p. 16), a Assíria, após um período em que teve de lidar com questões internas, manteve suas fronteiras contra incursões externas e começou a ter novamente controle sobre o território que a circundava, no final do décimo século a.C. A cada rei que subia ao trono, a Assíria expandia ainda mais seu território, tanto ao sul, onde se localizava a região de Babilônia, como a oeste, alcançando os reinos que faziam parte do Levante e finalmente o mar mediterrâneo.

A Assíria emerge do declínio para se tornar o primeiro grande império mundial nos dias de Assurdã II (935-912 a.C.) e Adadenirari II (912-891 a.C.). O império foi consolidado pelas conquistas de Assurnasirpal II (884-859 a.C.) e seu filho Salmaneser III (859-824 a.C.), que estenderam as fronteiras do império. Durante a dinastia sargonida, fundada por Sargão II, o império alcançou seu auge, e foi caracterizado por sua rica atividade literária e pelas expansões territoriais (NEGEV; GIBSON, 2001, p. 34). No entanto, foi durante o reinado de Assurnasirpal II que a arte assíria teve uma grande 
evolução que se estendeu até o reinado de Assurbanipal (669-627 a.C.). Quando Assurdã II subiu ao trono, a cidade de Assur ainda era a capital do Império Neoassírio. De acordo com Curtis e Reade (1995, p. 22-23, tradução nossa), Assur "era coroada com antigos templos e palácios, e lá havia uma tradição de peso sobre o local, inibindo qualquer rei que valorizasse seus poderes como governante secular mais altamente do que seu status religioso". No entanto, Assur estava situada na borda sul do coração da Assíria e, portanto, não era um local que oferecesse um bom centro de comunicações para o império, além da redistribuição militar e administração econômica (CURTIS; READE, 1995, p. 23).

Apesar de o rei que sucedeu Adadenirari II, Tuculti-Ninurta II, neto de Assurdã II, ter movido a capital de Assur para a cidade de Nínive, houve muita resistência por parte da população, justamente pelo caráter religioso e tradicional que Assur representava para o povo assírio. No entanto, foi no reinado de Assurnasirpal II que as mudanças dramáticas foram tomadas com relação à mudança da capital, transferida para a cidade de Calá e também referenciada pelo nome de Ninrode, uma cidade que se situava entre Assur e Nínive. Nesta cidade, Assurnasirpal II construiu um palácio que ofuscou a todos os palácios anteriores a ele. Seus muros coloridos, alinhados com painéis de pedra eram inscritos com o nome do rei e seus feitos (CURTIS; READE, 1995, p. 23). Esse palácio também conhecido como Palácio Noroeste e foi descoberto por Austen Henry Layard que, apesar de ser diplomata, tinha um grande interesse por civilizações antigas, além de ter sido patrocinado pelo museu britânico, o que foi essencial para o sucesso das escavações, não apenas em Ninrode, mas principalmente em Nínive, onde ele também foi responsável pelas escavações do Palácio Sudoeste do rei Senaqueribe.

O Palácio Noroeste de Assurnasirpal II é de grande importância para o estudo da arte no período neoassírio, pois aparentemente Assurnasirpal estabeleceu um modelo para os seus sucessores. Este é o palácio mais antigo, conhecido por conter relevos de pedra esculpida, figuras de leões guardiões e touros com asas e cabeças humanas, este último também conhecido como lamassu, uma divindade de proteção (BIENKOWSKI; MILLARD, 2000, p. 38). Os relevos e as esculturas encontradas nos palácios assírios possuíam propósitos específicos, tanto políticos como religiosos. São igualmente conhecidos por demonstrar a força e o poder dos governantes. As esculturas consistiam em grande parte em painéis de pedra, os quais originalmente estavam alinhados nas paredes dos palácios e foram esculpidos entre 870 e 620 a.C. De acordo com Curtis e Reade (1995, p. 39, tradução nossa):

os relevos de narrativa demonstram as conquistas de vários reis nas guerras, na caça e em obras públicas, os quais eram temas padrão da arte mesopotâmica de 3500 a 300 a.C., glorificando o poder real e a responsabilidade, uma vez que era dever do rei honrar aos deuses, proteger o estado dos inimigos e promover a prosperidade e o prestígio nacionais.

A demonstração de força e poder do deus Assur, do qual os reis consideravam ser legítimos representantes na Terra, também era algo de destaque na arte desse povo. Esse papel do rei como representante de uma divindade celestial não tinha apenas uma conotação religiosa, mas também político-militar. De acordo com Laato (1995, p.199-200, tradução nossa): 
os relatórios oficiais das campanhas militares no Antigo Oriente Próximo eram profundamente influenciados pela ideologia político-religiosa prevalescente. $O$ rei era considerado sob a proteção dos deuses e isso era usado para legitimar sua posição diante do seu povo. Essa legitimação implicava as campanhas militares reais serem consideradas como estando sob bênção divina. Havia a crença de que os deuses iriam prover o rei e seu exército e cuidar para que seus inimigos fossem derrotados. Pode-se dizer que uma expectativa social conectada com uma legitimação político-religiosa do rei forçava-o a fornecer uma resposta. Uma campanha militar de sucesso provocava uma resposta positiva na sociedade, especialmente quando ela tinha a oportunidade de celebrá-la. As cerimônias oficiais eram arranjadas quando o exército real vitorioso retornava da batalha. Outro importante modo de comunicar essa vitória era por meio de inscrições e relevos que eram exibidos em locais públicos.

Além de ser invencível, o rei tinha os deuses a seu lado, o que o desobrigava de justificações para os atos que realizava. Ele não era apenas um representante do deus Assur na Terra, acumulava também a função de sumo sacerdote e cabia a ele transmitir a glória desse deus pelo mundo. Isso poderia ser conquistado pela tarefa real de proteger o reino contra os inimigos, e os deuses, segundo o pensamento assírio, contemplavam com alegria a derrota e morte dos inimigos do estado (READE, 1979, p. 332). Uma derrota militar assíria, no entanto, poderia ser vista de forma negativa pela sociedade, demonstrando que o rei não era mais favorecido pelos deuses e ele ficava sob a ameaça de perder seu direito divino perante o povo. Todavia, ao sofrer uma derrota militar, o rei tinha a oportunidade de utilizar-se de inscrições e relevos para reportar-se ao seu povo e permanecer como governante legítimo. Estes permitiam que o rei demonstrasse que havia sido vitorioso, uma vez que textos e figuras eram considerados como refletindo a realidade histórica no antigo Oriente Próximo (LAATO, 1995, p. 200). Ao contrário das civilizações modernas, nas quais existem instituições e escolas de pensamento que formulam um pensamento crítico com relação ao propósito e a exatidão de certos documentos e acontecimentos históricos e podem questioná-los, essa realidade era inexistente no período assírio. Dessa forma, era mais fácil para o rei e sua corte manipularem a opinião pública, e a evolução da arte em relevos nesse período teve um papel primordial para a concretização desse discurso propagandístico. Para que o ser humano se identifique ou tenha o sentimento de pertencimento a um determinado grupo, é necessário que exista um mundo de sentido simbólico comum, que é a cultura. O passado é uma criação dessa cultura e evoca a necessidade de sentido e de referências de um dado presente. Essa construção de identidade se dá por meio da comunicação e da interação entre os indivíduos de uma sociedade (POZZER, 2018, p. 47-48). Além disso, Pozzer (2018, p. 55), concordando com Assmann, ressalta que "podemos incluir nesse sistema simbólico não só a linguagem, mas também ritos, motivos, ornamentos, monumento e imagens. Tudo pode se tornar signo para codificar este caráter comum". Os assírios, assim como qualquer outro povo, possuíam uma identidade nacional, e os artistas e a corte real souberam utilizar esse sentimento nacional e transformaram-no em algo tangível.

Deve-se observar também que a arte e os documentos escritos assírios são inseparáveis, porque se complementam. Esses escritos poderiam fazer parte desse 
conjunto artístico, como é o caso das inscrições cuneiformes que são encontradas nos relevos e nas esculturas dos palácios dessa civilização. Essas inscrições poderiam conter detalhes básicos a respeito das esculturas ou detalhes mais pormenorizados sobre a descrição não apenas do local do acontecimento e da identificação de figuras, como é o caso de alguns relevos, mas também a respeito de conquistas pessoais do rei. Um claro exemplo é uma inscrição de Assurnasirpal II em referência ao seu palácio:

Eu fundei nesse local um palácio como minha residência real e para meu prazer senhorial pela eternidade. Eu o decorei em estilo esplêndido [...] Que um príncipe posterior restaure suas porções enfraquecidas e restaure meu nome inscrito em seu lugar. Então, Assur irá ouvir suas preces. Ele não pode esquecer meu poderoso palácio, minha residência real de Calá, nem o abandonar diante de seus inimigos. Ele não deve remover suas portas, vigas ou pregos de bronze e colocá-los em outra cidade e em outro palácio [...] Ele não deve bloquear sua porta. Ele não deve torná-lo um armazém, nem uma prisão [...] Ele não deve permitir a desintegração do palácio devido à negligência, deserção ou falta de renovação. Ele não deve se mudar para outro palácio, seja dentro ou fora da cidade, ao invés do meu palácio (GRAYSON, 1991, p. 252, tradução nossa).

Todavia, não se passou muito tempo até que os sucessores de Assurnasirpal II mudassem de seu palácio para outro. Esarhaddom, por exemplo, removeu esculturas presentes no palácio de Assurnasirpal II e as introduziu em seu novo palácio, também em Calá (READE, 1965, p. 120). Os documentos escritos também poderiam estar separados do conjunto artístico, como é o caso do Prisma de Senaqueribe, no qual se encontra uma lista das campanhas militares de Senaqueribe até o início da guerra final contra a Babilônia, consistindo de um prisma hexagonal feito de barro.

\section{O PROGRAMA DO PALÁCIO DE ASSURNASIRPAL II}

A distribuição e a orientação tanto dos conjuntos artísticos, como da arquitetura, não se davam de forma desorganizada ou aleatória no palácio, uma vez que cada cômodo servia a um propósito específico. Podem-se observar essas características tanto no palácio de Assurnasirpal II, como nos palácios de seus sucessores (RUSSELL, 1998, p. 662-665). Exibições modernas dessas esculturas e relevos podem guiar o observador para fora de seu contexto original, uma vez que, segundo Reade (1979, p. 330, tradução nossa) "elas sempre consistem de fragmentos - várias placas de comprimento, talvez, mas fragmentos - do que eram esquemas muito complicados de decoração incluindo também pinturas que abrangiam palácios inteiros". Russell (1998, p. 663) conjectura que as decorações de relevo de todo o palácio são uma expressão visual da ideologia real de Assunarsirpal II, sendo os pontos principais: sucesso militar, serviço aos deuses, proteção divina e prosperidade. Ele chega a essa conclusão ao citar o "princípio de consumo conspícuo", de Bruce Trigger, ou seja, despesas excessivas de energia, tanto de recursos naturais como de pessoas.

Enquanto o próprio palácio simbolizava em mais alto nível o princípio de consumo conspícuo, suas altas muralhas e a elevação da cidadela eram um sinal claro de exclusão 
por parte do rei e da elite do restante da população, que não poderia participar das atividades reais lá realizadas. Essas atividades incluíam em grande parte audiências reais, entretenimento, rituais e cerimônias, também engajadas no princípio de Trigger, e que tinham como objetivo alcançar a elite que participava dessas atividades (RUSSELL, 1998, p. 663). Em contraste, a grande massa da população iria absorver a mensagem de poder e exclusão por meio da arquitetura. A exceção talvez tenha sido a inauguração do palácio, para a qual foram convidadas 47.074 pessoas de "sua terra", cerca de 16 mil da capital Calá e 1.500 oficiais, de acordo com a Estela do Banquete de Assurnasirpal (KAELIN, 2018, p. 486). Não há como ter uma noção exata da fachada externa do palácio. Em palácios posteriores, como os de Sargão II e Senaqueribe, as esculturas gigantescas, incluindo o lamassu e as figuras humanas agarrando leões, eram colocadas no exterior do palácio e provavelmente eram visíveis de uma certa distância (READE, 1979 , p. 335-336). Os palácios também eram decorados parcialmente com figuras mágicas, que segundo a crença desse povo, afastavam doenças e a má sorte. Essas figuras ao redor do 9 século a.C. eram representadas por tipos assírios, mas foram se tornando menos frequentes com o passar dos séculos enquanto figuras vindas da Babilônia ou da parte oeste do império foram sendo acrescentadas, demonstrando que os assírios podiam adotar qualquer coisa que os atraísse, não importando sua origem. Essas figuras mágicas foram encontradas nas entradas do palácio e podiam servir não apenas para o propósito de impressionar seres humanos, mas também visitantes sobrenaturais (READE, 1979, p. 335-336). Sendo assim, para muitos assírios comuns, essas eram as únicas figuras do palácio a que eles tinham acesso durante toda a sua vida, o que possivelmente podia levar a uma grande expectativa imaginária do que havia dentro do palácio.

Kaelin (2018, p. 479-486) sugere que embora muitas características iconográficas fossem novas na Assíria com esse programa de Assurnasirpal, elas eram imagens básicas nos templos do Egito no Reino Novo. Os temas representados por todo o palácio tinham como propósito enviar uma mensagem aos seus espectadores de que Assurnasirpal era um rei poderoso e de muito sucesso (caças, guerras, tributos), mas também muito próximo do mundo sobrenatural (figuras mágicas, representações divinas). Essa prática de utilização de relevos como forma de decoração arquitetônica não foi a única a ser importada pelos Assírios. Fragmentos de uma estátua colossal que media ao redor de 3 metros de altura foram encontrados em Assur. Essas estátuas não eram comuns na Assíria, sendo mais comuns em regiões vizinhas como o norte da Síria. As esculturas em forma de leões e touros alados que adornavam os palácios também não tinham sua origem na Assíria, sendo seu uso mais antigo atestado pelos hititas em sua antiga capital Hattusas, sítio localizado no leste da moderna Turquia (TAKLA, 2008, p. 162). Contudo, deve-se notar que o ponto em comum entre os hititas e os assírios, no quesito artístico, se dava com a prática de decorar muros e pilares com imagens e portais com animais. Mas com relação às imagens em si, não há muitas semelhanças entre os temas, qualidade e complexidade (KAELIN, 2018, p. 480). Portanto, pode-se notar que os assírios não se importavam em adquirir ou importar características culturais de povos distintos, que em muitos casos podiam ser nações subjugadas. 


\section{A ARTE NO PERÍODO DE SENAQUERIBE}

Em 705 a.C., Sargão II liderava uma de suas campanhas militares. Ele havia se tornado rei da Babilônia em 709 a.C. e após Merodaque-Baladã ter-Ihe pago um alto tributo, uma vez que sua cidade estava cercada, Sargão se retirou. Um novo inimigo, no entanto, se levantou contra os assírios. Os cimérios, um povo indo-europeu, entraram pela Anatólia ao norte, se moveram pelo território de Urartu e cercaram a Assíria (NEMET-NEJAT, 2002, p. 39). Em resposta a essa invasão, Sargão batalhou contra os cimérios em 705 a.C., mas foi morto no campo de batalha, um tipo de morte incomum para um rei mesopotâmico. O corpo de Sargão II foi perdido na batalha e nunca mais encontrado. Seu filho mais velho e sucessor no trono, Senaqueribe, ascendeu ao trono da Assíria após esses eventos.

Senaqueribe tinha ao redor de quarenta anos de idade quando ascendeu ao trono e reinou por quase vinte quatro anos (704-681 a.C.). Segundo Grayson e Novotyn (2012, p. 1, tradução nossa) "o fato de os assírios não conseguirem recuperar o corpo de Sargão e de Senaqueribe não poder realizar um funeral para seu pai como a tradição prescrevia foi considerado como pouco auspicioso". Nabû-zuqup-kenu, que serviu como escriba chefe para os reis Sargão II e Senaqueribe, sugeriu em seus estudos sobre a morte de Sargão que Senaqueribe transferiu imediatamente a cidade real para Nínive, uma vez que ele temia que o fantasma não enterrado de seu pai ainda estivesse presente na cidade real de Dur Sharrukin (GRAYSON; NOVOTYN, 2012, p. 1). Essas razões religiosas explicam o porquê de Senaqueribe ter mudado a capital para Nínive, a qual já era um dos principais centros religiosos do império assírio, e a partir de então também transformou-se no centro político tanto da Assíria, como do Oriente Próximo naquele tempo. Ao se mudar para Nínive, Senaqueribe deu início à construção de um palácio ao qual ele se referiu em documentos posteriores como "palácio sem rival". Esse palácio foi construído no sudeste do monte Kouyunjik, que era abrangido pelos muros da antiga Nínive. As paredes de setenta cômodos dessa estrutura eram revestidas com placas de calcário esculpidas em relevos com cenas militares das campanhas de Senaqueribe (RUSSEL, 1991, p. 1). Ele afirmou que seu palácio foi construído com a ajuda de trabalho estrangeiro, e em seus anais, ele fornece a nacionalidade dos que trabalharam para ele: "o povo da Caldéia, os arameus, os Mannai, o povo de Kueand Hilakku, que não se submeteu ao meu jugo, eu os despachei de suas terras, e os fiz carregar cestas e tijolos" (LUCKENBILL, 1924, p. 71).

O que se sabe atualmente a respeito do Palácio Sudoeste de Senaqueribe é o resultado de muitas escavações em um período de aproximadamente 120 anos (de 1847 a 1967). A maioria das escavações foi conduzida por Austen Henry Layard, que também nomeou o "Palácio sem Rival" como "Palácio Sudoeste". Layard escavou em Nínive, e em particular, no Palácio Sudoeste de 1845 e 1851, um período dividido em duas campanhas. Na primeira campanha, que ocorreu de 1845 a 1847, ele se concentrou nas ruínas de Ninrode, e particularmente no Palácio de Assurnasirpal. Nesse mesmo período, ele enviou uma pequena parte dos homens que estavam trabalhando nas escavações para cavarem covas na parte do sul do monte Kouyunkij, onde se localizava a parte mais alta do monte e onde as ruínas mais preservadas poderiam ser encontradas (RUSSEL, 1991, p. 34). Layard estava certo, e o trabalho posterior demonstrou que de fato esse era o local do palácio de Senaqueribe. No entanto, as ruínas do edifício estavam a uma profundidade de 6 a 10 metros, levando vários dias para os homens 
escavarem fundo o bastante e se depararem com uma entrada formada por bois com asas e cabeças humanas, ou lamassu. Layard resumiu seu trabalho e conquistas:

Nesse magnífico edifício, eu abri não mais que setenta e um corredores, quartos, e passagens, nos quais os muros, quase que sem exceção, foram esculpidos com placas de alabastro reproduzindo as guerras, os triunfos e os grandes feitos do rei assírio. Por um cálculo aproximado, cerca de 9880 pés, ou quase duas milhas de relevos, com vinte e sete portais formados por bois com asas e esfinges de leões colossais foram descobertos somente daquela parte da construção explorada durante minhas pesquisas (LAYARD, 1853, p. 589).

De acordo com os planos desenhados por Layard, no Palácio Sudoeste os cômodos eram divididos e conectados entre si de uma forma peculiar. Ao adentrar o palácio, o visitante logo se deparava com a suíte de recepção. Esta dava acesso à sala do trono, que assim foi identificada por causa de seu tamanho, plano e localização (RUSSEL, 1991, p. 47). Além disso, deve-se notar que essa porção preservada do plano de Layard é virtualmente idêntica à sala do trono de Sargão II, em seu palácio em Dur Sharrukin, cômodo 7. Outros cômodos de grande importância são os pátios 7 e 19. Além de o pátio 19 ser um local importante no palácio, dado o seu tamanho e localização, ele continha um par de leões com cabeças humanas colossais esculpidos em calcário grosso e introduzia o cômodo 36, um pequeno quarto onde os relevos da batalha de Laquis foram encontrados. Felizmente, esse cômodo está entre os mais bem preservados do palácio e sua série de relevos de ao menos três paredes se encontra hoje no museu britânico, enquanto o quarto muro é conhecido apenas pelas descrições de Layard (RUSSEL, 1991, p. 64). O pátio onde o cômodo de Laquis está localizado aparentava ser decorado exclusivamente com cenas da terceira campanha de Senaqueribe para o oeste (RUSSEL, 1991, p. 161-164, 172-174), e se destaca por ter sido um local de importância no palácio. Os relevos de Laquis ganharam proeminência pela sua configuração arquitetônica e o acesso ao cômodo 36 através do Pátio 19, que era realizado por uma série de três portais monumentais, cada um sendo decorado com um par de lamassu. Esses lamassu decresciam de um tamanho de 5,5 metros o mais externo para 3,5 metros, o mais interno. Segundo Layard (1853, p. 230, tradução nossa):

[...] seria muito difícil de conceber qualquer arranjo arquitetônico interior mais impositivo do que esse grupo triplo de formas gigantescas visto em perspectiva por pessoas que estavam no centro do corredor; vagamente iluminado por cima e harmoniosamente colorido ou coberto com ouro, como os querubins no templo de Salomão.

As paredes do cômodo 36 eram provavelmente todas cobertas pelos relevos de Laquis. Os desenhos de Austen Layard acerca do palácio marcam treze painéis enumerados ao longo das paredes no cômodo, e em sua descrição escrita ele confirma essa informação (USSISHKIN, 1982, p. 71).

De acordo com Ussishkin (1982, p. 71) Layard estava errado, uma vez que "doze painéis aparentemente arranjados em ordem consecutiva estão preservados atualmente; eles são equivalentes aos painéis de Layard de número (5-13), somente 
nove painéis de acordo com essa enumeração. Os painéis que estavam faltando no começo da série (1-4) não foram documentados, e a única pista do seu conteúdo é um comentário de Layard, em que descreve que eles consistiam de corpos grandes de cavaleiros e carruagens (LAYARD, 1853, p. 149). Em ordem consecutiva da esquerda para a direita é exibido a infantaria atacando, a tomada de Laquis (Imagem 2), os despojos e os deportados, os cativos, Senaqueribe sentado em seu trono, a tenda real e carruagens e no final o campo assírio. Ussishkin (1982, p. 71, tradução nossa) nota que

a seção que retrata a tomada de Laquis, esculpida no lado direito do painel 2 até o lado esquerdo do painel 4 era aparentemente colocado no centro da parede traseira, em frente à entrada. Devido aos efeitos de luzes, qualquer um que passasse através da entrada principal iria perceber a iminente tomada de Laquis procedendo através das entradas.

De acordo com Russel (1993, p. 68), "por causa da combinação da localização central e efeitos de perspectiva fazem de Laquis o ponto focal do grupo de aposentos, um visitante poderia justificadamente concluir que a rendição de Laquis (Imagem 1) era o ponto alto da campanha ocidental de Senaqueribe". Qual seria, no entanto, a razão da cidade de Laquis no território de Judá ter alcançado um lugar de destaque no palácio de Senaqueribe? O contexto militar da época e os documentos escritos sugerem que devido a revoltas no império lideradas por Ezequias, rei de Judá, Senaqueribe, após lidar com uma revolta babilônica liderada por Merodaque-Baladão, deu atenção para o oeste do império. Movendo-se para o sul ao longo da costa, ele encontrou resistência na cidade de Tiro, substituindo seu rei que havia fugido para o Chipre por um rei de sua escolha. No entanto, os reinos de Asquelom, Ecrom e Judá permaneceram firmes. Senaqueribe avançou e derrotou um exército combinado de egípcios e etíopes na planície costeira, os quais tinham vindo para auxiliar os rebeldes. De acordo com Bright (2000, p. 286), "Senaqueribe então tomou Ecrom e outras cidades filisteias à vontade, punindo ofensores com execuções e deportações". Após esses eventos, Senaqueribe tinha o caminho livre para lidar com o reino de Judá. Os anais de Senaqueribe trazem em detalhes parte dessa expedição, que está registrada no Prisma de Senaqueribe:

\begin{abstract}
Com relação a Ezequias, o judeu, que não se submeteu ao meu jugo, 46 das suas poderosas cidades muradas, como também pequenas cidades da vizinhança incontáveis; nivelando com aríetes e trazendo máquinas de cerco, atacando e invadindo a pé, por minas, túneis e fendas, eu cerquei e tomei (essas cidades). 200.150 pessoas, grandes e pequenas, homens e mulheres, cavalos, mulas, jumentos, camelos, gado e ovelhas incontáveis; eu os removi deles e contei como saque. Ele, como um pássaro em uma gaiola, eu tranquei em Jerusalém, sua cidade real (LUCKENBILL, 1924, p. 32-33, tradução nossa).
\end{abstract}

Curiosamente, Laquis não é mencionada nos anais de Senaqueribe ou em qualquer inscrição, exceto a do cômodo 36 (Imagem 2). A única maneira de identificar a identidade da cidade é pela inscrição que se encontra em frente à figura do rei, onde lê-se: "Senaqueribe, rei do universo, rei da Assíria, sentado em uma cadeira de sedan, os despojos de Laquis passam diante dele" (COGAN, 2008, p. 125). Uma das possíveis 
razões para que a cidade de Laquis tenha sido retratada de forma destacada nos relevos de Senaqueribe é o seu posicionamento no reino como a segunda cidade de maior importância a partir do século 10 a.C., atrás apenas de Jerusalém (BIENKOWSKI; MILLARD, 2000, p. 173). O fato de a cidade de Jerusalém não ter sido retratada nos relevos e sim a cidade Laquis, juntamente com a evidência documental de Senaqueribe em que ele atesta ter "trancado" Ezequias como um pássaro em uma gaiola em Jerusalém, não permitem a interpretação a respeito de uma conquista da cidade real de Judá. Senaqueribe, de alguma forma, foi incapaz de conquistar a cidade principal do rei que havia iniciado a rebelião levantina contra a Assíria e acabou por utilizar a segunda cidade em importância como seu triunfo.

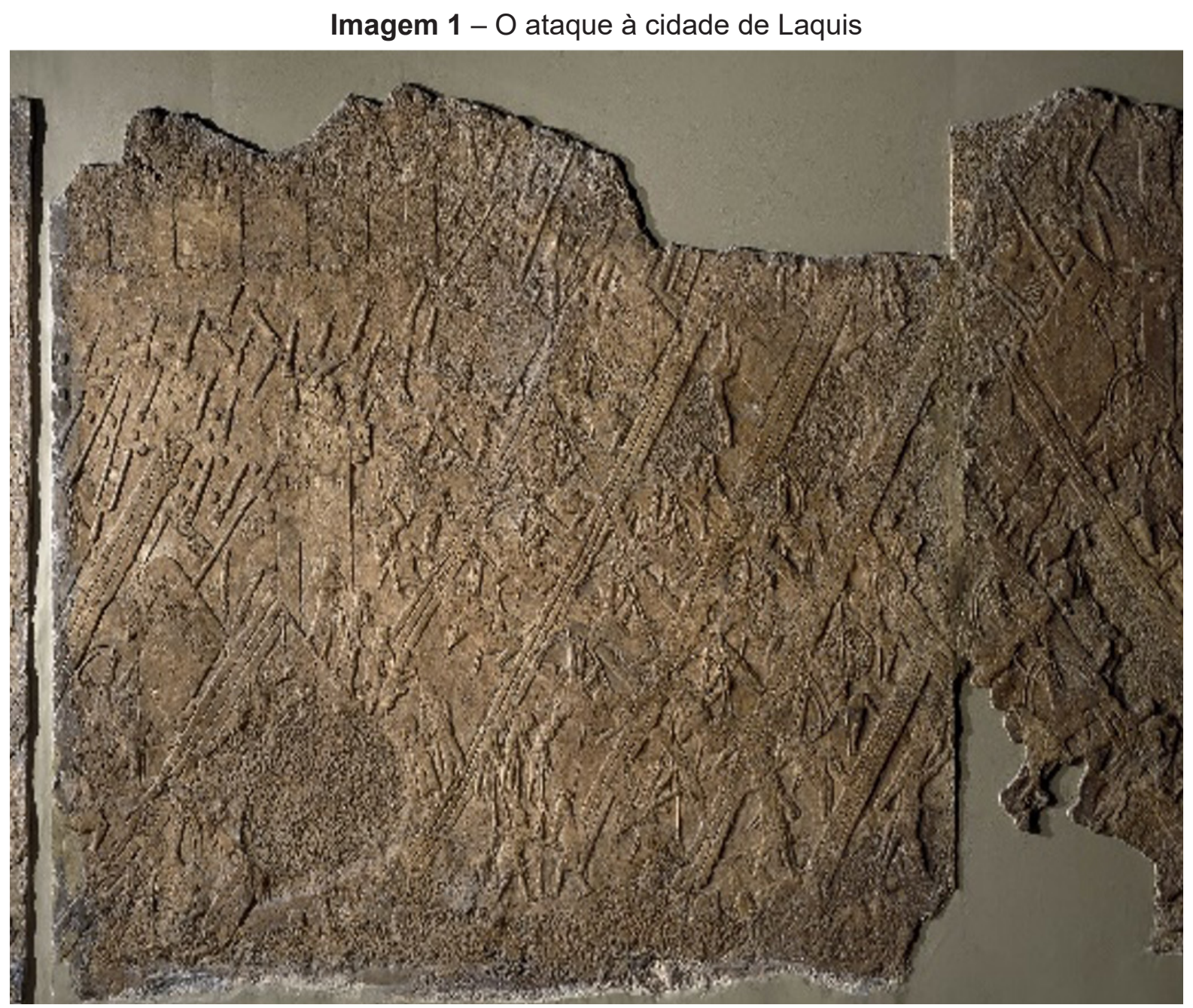

Fonte: () The Trustees of the British Museum.

\section{INOVAÇÃO E AUDIÊNCIA NOS RELEVOS DE SENAQUERIBE}

Como apontado anteriormente, os relevos retratavam uma miríade de temas mesopotâmicos que eram transmitidos desde 3500 a.C. e poderiam consistir em guerras, caças, obras públicas, além de representações de figuras mágicas. No reinado de Senaqueribe, no entanto, mudanças ocorreram com relação ao aspecto 
artístico dos relevos. Para aqueles que viveram naquele tempo e haviam visto os relevos anteriores de outros palácios, os relevos narrativos eram surpreendentemente inovadores, provendo uma efetiva sugestão de profundidade. De acordo com Russel:

As placas de relevo narrativo dos antecessores de Senaqueribe são divididas horizontalmente em dois registros por uma faixa levantada de inscrição. No resultante campo pictórico longo e relativamente estreito, as relações espaciais podem ser indicadas por uma das duas convenções. O mais comum era colocar todas as figuras em uma única linha de base, sendo a profundidade indicada por ter figuras mais próximas sobrepondo as mais distantes. Em composições organizadas dessa forma, a fluidez da narrativa dentro do registro é horizontal. Devido a todas as figuras serem arranjadas de forma horizontal e haver apenas uma única linha de caracteres no registro, somente uma única história pode ser contada em cada segmento vertical do registro (1993, p. 57, tradução nossa).

Imagem 2 - Senaqueribe sentado em seu trono contemplando a conquista da cidade. À sua frente, um pouco acima encontra-se a inscrição contendo a identificação da cidade

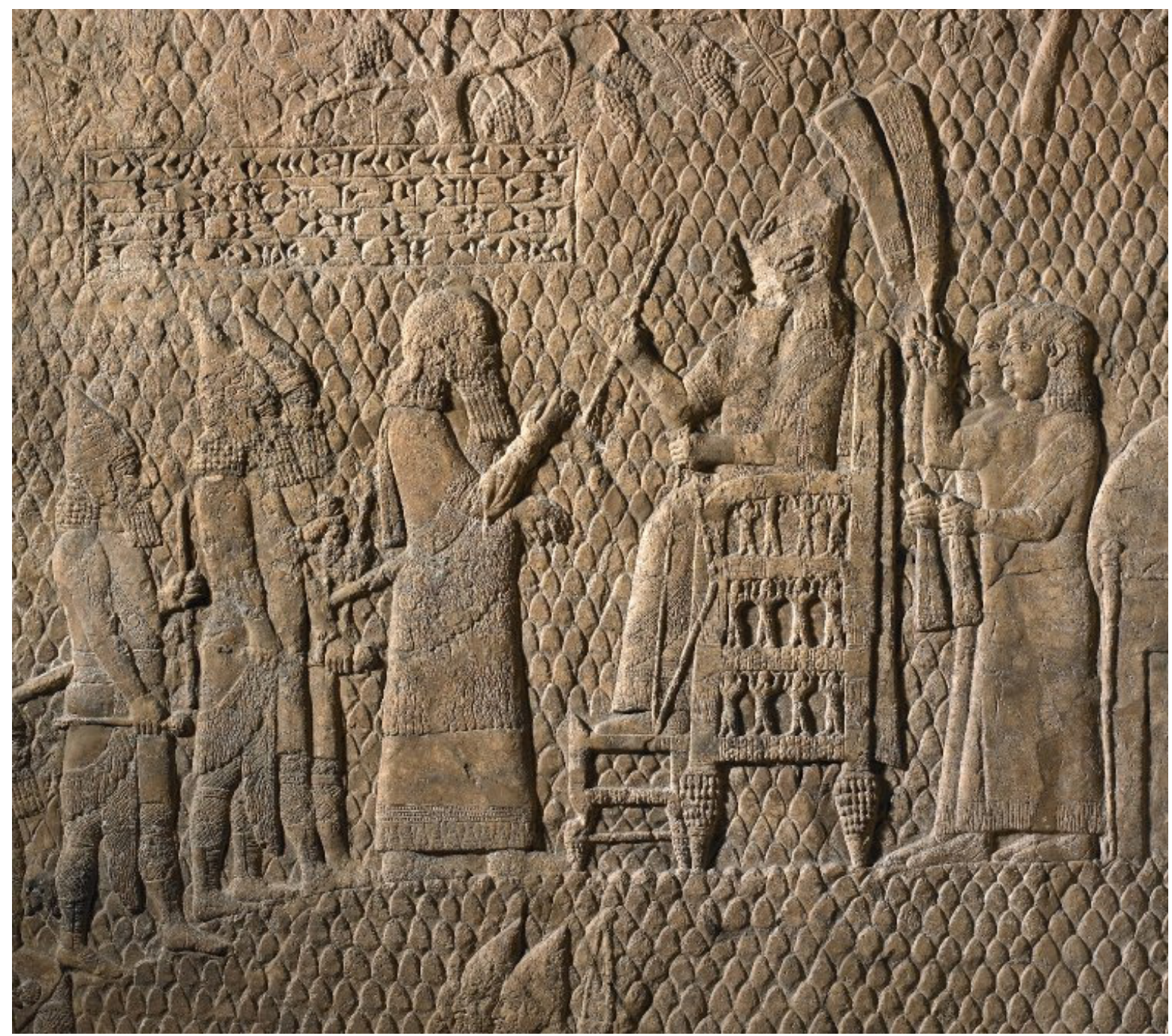

Fonte: () The Trustees of the British Museum. 
As figuras nos relevos encontrados no palácio de Senaqueribe, por outro lado, poderiam ser colocadas em qualquer lugar, e as figuras mais altas são entendidas por serem mais distantes do que as mais baixas. Essa convenção não foi "inventada" no tempo de Senaqueribe, mas era usada com pouca frequência antes de seu período. Esse sistema providencia uma sugestão mais satisfatória de profundidade, e, ao mesmo tempo, permite maior complexidade. A narrativa pode fluir vertical e diagonalmente, como também horizontalmente, com figuras acima e abaixo das primárias provendo informação adicional ou várias fileiras de personagens arranjados um acima do outro, cada um contando sua própria história (RUSSEL, 1993, p. 58). Em síntese, essa mudança significava que mais figuras de diferentes escalas poderiam ser incorporadas dentro de composições individuais e, consequentemente, mais detalhes circunstanciais poderiam ser providenciados. Além disso, nos relevos de Senaqueribe é possível vê-lo tomando uma posição menos dominante dentro da narrativa em contraste com seus antecessores. Senaqueribe nunca aparece lutando pessoalmente, mas ele é sempre o foco das composições, por estar sentado em seu trono, esperando e recebendo os prisioneiros e os saques da cidade conquistada. A audiência que estava em contato com os relevos era muito maior do que a das escritas narrativas no palácio de Senaqueribe. Algumas considerações a respeito da audiência das narrativas escritas devem ser feitas para que se possa entender o conceito propagandístico assírio encontrado nos relevos. As narrativas escritas eram produzidas para um grupo exclusivo, e Russel destaca:

Qualquer visitante externo iria enfrentar ao menos cinco
dificuldades substanciais em interpretá-las. Primeiro, grande
parte dos visitantes forasteiros não era alfabetizada. Segundo,
mesmo se eles pudessem encontrar alguém para ler o texto,
grande parte dos forasteiros - e até dos visitantes assírios -
provavelmente não poderia entender acadiano, que estava
sendo substituído gradualmente pelo aramaico como língua
primária falada no império. Terceiro, mesmo visitantes assírios
que entendiam acadiano teriam dificuldades para entender as
inscrições do palácio, pois eram quase sempre escritas em
dialeto babilônico, em vez de assírio. Em quarto lugar, mesmo se
eles passassem pelos primeiros três obstáculos, necessitariam
ter tempo suficiente para ler esses textos, os quais são muito
longos e envolventes. Finalmente, poucas pessoas fora da corte
teriam o background cultural necessário para compreender
completamente a titulatura, o que pressupõe uma familiaridade
de alto nível com a ideologia imperial assíria (1993, p. 70 ,
tradução nossa).

Portanto, seria muito improvável que um visitante do palácio tivesse o tempo e o conhecimento necessários para passar por todas as inscrições e perceber que a campanha de Senaqueribe em território judaico não foi muito bem-sucedida. Por essas razões, o grupo que poderia facilmente acessar o conteúdo das narrativas escritas era a elite administrativa assíria, que tinha a confiança do rei. Takla $(2008$, p. 136) ressalta esse ponto ao mencionar que as inscrições funcionavam em dois outros níveis não verbais. Os súditos dos reis assírios tinham a compreensão de que somente uma pessoa com autoridade e prestígio elevados deveria ordenar tais empreendimentos. Além disso, o controle dos escribas por parte do rei afirmava a sua legitimação e poder. Isso 
também era um aspecto importante para Senaqueribe, uma vez que o perigo real que ele poderia enfrentar não eram seus inimigos vindos de países distantes, mas em seu próprio palácio. A narrativa visual, como afirmado aqui, poderia alcançar uma audiência muito mais abrangente do que as narrativas escritas, incluindo não apenas cortesãos letrados, mas também assírios analfabetos e estrangeiros, que poderiam reconhecer os locais de batalha e seu povo e terra nos relevos. Mas, um detalhe não pode ser descartado: nas narrativas visuais, a campanha malsucedida no território judaico não precisaria ser necessariamente mencionada pelos artistas de Senaqueribe. A queda de Laquis nas mãos dos assírios demonstrou para todos o que eles já sabiam, que os assírios eram invencíveis e o preço da resistência era a derrota (RUSSEL, 1993, p. 70). Entretanto, isso não exclui a veracidade dos eventos retratados nos relevos, mas demonstra que o rei e sua corte poderiam omitir alguns eventos para difundir a ideia de estabilidade e poderio real.

\section{CONSIDERAÇÕES FINAIS}

As diversas formas de arte provenientes da mesopotâmia tradicionalmente retratavam temas de conquistas militares, na caça e em obras públicas realizadas por vários reis, além de temas religiosos. O rei era considerado como o legítimo representante dos deuses na Terra e se utilizava desse conceito para legitimar sua posição entre seu povo. Além disso, suas campanhas militares eram consideradas sob a proteção divina. No entanto, o rei poderia sofrer um revés e ser ameaçado de perder seu direito real perante o povo. Uma vez que as inscrições e relevos eram consideradas como refletindo a realidade histórica no Antigo Oriente Próximo, os reis se utilizavam dessa crença em seu favor, sempre demonstrando campanhas militares vitoriosas e a humilhação de seus inimigos. Assurnasirpal II estabeleceu um padrão para os seus sucessores ao construir seu palácio no qual a arte fora colocada em cada cômodo de forma organizada e sistematizada. Os temas artísticos exibidos em seu palácio tinham como propósito reforçar o poder real e sua legitimidade como representante de Assur na Terra. A própria arquitetura do palácio sinalizava ao seu povo um status de poder da realeza e de exclusão do povo comum. O rei Senaqueribe deu prosseguimento a esse modelo instituído por Assurnasirpal II. Ele utilizou-se de inovações artísticas, permitindo que mais detalhes pudessem ser inseridos em uma mesma composição. Em seu "Palácio sem Rival", os cômodos foram organizados de tal maneira que pudessem direcionar os seus visitantes de forma sistemática às recentes conquistas de Senaqueribe no oeste do império.

Pode-se observar, no entanto, que as narrativas assírias ou documentos escritos diferem dos relevos encontrados no palácio de Senaqueribe. A audiência para os dois é claramente separada no aspecto de conhecimento prévio e grau de instrução. Senaqueribe não poderia dizer que sua campanha no Levante foi um completo sucesso, uma vez que ele não foi capaz de conquistar Jerusalém, e esta não aparece nos relevos, a despeito de ser a principal cidade do reino de Judá. Uma vez que seria muito difícil aos visitantes do palácio de Senaqueribe ler e entender as inscrições, inclusive para visitantes instruídos, os relevos demonstrando o poder e a glória do rei e seu exército certamente causariam o efeito desejado promovendo o respeito ao rei pela audiência a qual ele pretendia alcançar. 
Pozzer (2018, p. 56), referindo-se aos relevos que retratam Laquis, ressalta que "ainda que essas cenas estejam impregnadas de um discurso ideológico e propagandístico, evocando uma íntima relação entre estética e política ou criando uma imagem ilusória, elas não deixam de conter verdades históricas". Pode-se concluir, portanto, que discursos propagandísticos poderiam ser utilizados como um meio de permanência no poder, prática esta que remonta ao primeiro milênio a.C., e que mesmo a verdade parcial poderia ser utilizada como legitimação sobre uma determinada sociedade. Embora os relevos palacianos pudessem alcançar uma parcela maior da população, considerando-se leigos e estrangeiros, ainda assim esse alcance não era o suficiente, uma vez que o acesso ao palácio não era completamente aberto ao público. No entanto, a audiência a qual de fato o rei pretendia alcançar, era a elite, que participava das solenidades reais e da qual o rei necessitava de apoio, especialmente em ocasiões em que o rei enfrentava um revés militar, pois como mencionado anteriormente, os principais inimigos dos reis assírios não estavam em países distantes, mas circulando em seu próprio palácio.

\section{REFERÊNCIAS}

BIENKOWSKI, P.; MILLARD, A. Dictionary of the Ancient Near East. $2^{\mathrm{a}}$ ed. Philadelphia: University of Pennsylvania Press, 2000.

BRIGHT, J. A History of Israel. Louisville: Westminster John Knox Press, 2000.

COGAN, M. Bound for Exile: Israelites and Judeans under Imperial Yoke. Jerusalem: Carta Jerusalem, 2008.

CURTIS, J. E.; READE, J. E. Art and Empire: Treasures treasures from Assyria in the British Museum. London: British Museum Press, 1995.

GRAYSON, A. K. Assyrian Rulers of the Early First Millennium BC I: (1114- 859 BC). In: GRAYSON, A. K. The Royal Inscriptions of Mesopotamia, Assyrian Periods. Toronto: Toronto University Press, 1991. v. 2, p. 288-293.

GRAYSON, A. K.; NOVOTYN, J. The Royal Inscriptions of Sennacherib, King of Assyria (704-681 BC), Part 1. In: GRAYSON, A. K.; NOVOTYN, J. (ed.). The Royal Inscriptions of the Neo-Assyrian Period. Pennsylvania: Einsenbrauns, 2012. v. 3.

KAELIN, O. Comparing Images - The Relief Programme in the Palace of Assurnasirpal II and the Egyptian Mortuary Temples of the New Kingdom. In: HOREJS, B. et al. (ed.) Proceedings of the $10^{\text {th }}$ International Congress on the Archaeology of the Ancient Near East. Wiesbaden: Harrossowitz Verlag, 2018. p. 479-496.

LAATO, A. Assyrian Propaganda and the Falsification of History in the Royal Inscriptions of Sennacherib. Vetus Testamentum, Leiden, v. 45, n. 2, p. 198-226, 1995. 
LAYARD, A. H. Discoveries in the Ruins of Nineveh and Babylon. London: John Murray, 1853.

LUCKENBILL, D. D. The Annals of Sennacherib. Chicago: The University of Chicago Oriental Institute Publications, 1924. v. 2.

MCLAUGHLIN, J. L. The Ancient Near East: an essential guide. Nashville: Abingdon Press, 2012.

NEGEV, A.; GIBSON, S. Archaeological Encyclopedia of the Holy Land. 4a ed. New York: The Continuum Publishing Group, 2001.

NEMET-NEJAT, K. R. Daily Life in Ancient Mesopotamia. Peabody: Hendrickson Publishers, 2002.

POZZER, K. M. P. Guerra, Violência e Memória Cultural nas Imagens Assírias. Anos 90, Porto Alegre, v. 25, n. 47, p. 39-59, jul. 2018.

READE, J. E. Twelve Ashurnasirpal Reliefs. Iraq, London, v. 27, n. 2, p. 119-134, 1965.

READE, J. E.; Ideology and Propaganda in Assyrian Art. In: MOGENS, T. L. (ed.) Power and Propaganda: A Symposium on Ancient Empires. Copenhagen: Akademisk Forlag, 1979. p. 329-343.

RUSSEL, J. M. Sennacherib's Lachish Narratives. In: HOLLIDAY, P. J. (ed.). Narrative and Event in Ancient Art. San Bernardino: Cambridge University Press, 1993. p. 55-73.

RUSSEL, J. M. Sennacherib's Palace Without a Rival at Nineveh. Chicago: The University of Chicago Press, 1991.

RUSSELL, J. M. The Program of the Palace of Assurnasirpal II at Nimrud: Issues in the Research and Presentation of Assyrian Art. American Journal of Archaeology, Boston, v. 102, n. 4, p. 655-715, 1998.

TAKLA, P.R. Desenvolvimento do esquema decorativo das salas do trono do período neoassírio (934-609 a.C.). 2008. Dissertação (Mestrado em Arqueologia) - Museu de Arqueologia e Etnologia, Universidade de São Paulo, São Paulo, 2008.

USSISHKIN, D. The Conquest of Lachish by Sennacherib. Tel Aviv: Tel Aviv University, 1982. 


\section{NOTAS}

\section{AUTORIA}

Bruno Alves Barros: Mestre. Doutorando, Universidade Eötvös Loránd, Escola Doutoral em História, Departamento de Assiriologia e Estudos Hebraicos, Budapeste, Hungria.

\section{ENDEREÇO PARA CORRESPONDÊNCIA}

1088 Budapest, Múzeum körút 4/F II. em, Hungary.

\section{ORIGEM DO ARTIGO}

Extraído da monografia "AArte como Elemento de Poder e Propaganda no Império Neoassírio", apresentada ao Programa de Graduação em História do Centro Universitário Internacional Uninter, em 2019.

\section{FINANCIAMENTO}

Não se aplica.

\section{CONSENTIMENTO DE USO DE IMAGEM}

Não se aplica.

\section{APROVAÇÃO DE COMITÊ DE ÉTICA EM PESQUISA}

Não se aplica.

\section{CONFLITO DE INTERESSES}

Não houve conflito de interesses.

\section{LICENÇA DE USO}

Este artigo está licenciado sob a Licença Creative Commons CC-BY. Com essa licença você pode compartilhar, adaptar e criar para qualquer fim, desde que atribua a autoria da obra.

\section{PUBLISHER}

Universidade Federal de Santa Catarina. Programa de Pós-Graduação em História. Portal de Periódicos UFSC. As ideias expressadas neste artigo são de responsabilidade de seus autores, não representando, necessariamente, a opinião dos editores ou da universidade.

\section{EDITORES}

Flávia Florentino Varella (Editora-chefe)

Tiago Kramer de Oliveira

Waldomiro Lourenço da Silva Júnior

\section{HISTÓRICO}

Recebido em: 2 de janeiro de 2020

Aprovado em: 9 de maio de 2020

Como citar: BARROS, Bruno Alves. A arte como elemento de poder e propaganda no Império Neoassírio. Esboços, Florianópolis, v. 27, n. 46, p. 494-510, set./dez. 2020. 